\title{
Coseismic deformation of the 2007 Chuetsu-oki earthquake derived from PALSAR/InSAR and its fault model
}

\author{
Taku Ozawa \\ National Research Institute for Earth Science and Disaster Prevention, Japan \\ (Received December 13, 2007; Revised April 1, 2008; Accepted April 15, 2008; Online published November 18, 2008)
}

\begin{abstract}
The 2007 Chuetsu-oki earthquake $\left(M_{\mathrm{j}} 6.8\right)$ occurred offshore of Niigata Prefecture, northeast Japan, on 16 July 2007. I applied PALSAR/InSAR to detect coseismic deformation associated with the earthquake. The interferogram generated from descending data revealed a slant-range shortening exceeding $20 \mathrm{~cm}$ in the coastal area of Kashiwazaki adjacent to the epicenter and a maximum slant range extension of approximately $15 \mathrm{~cm}$ southeast of the slant-range shortening pattern. The interferogram generated from descending data is consistent with GPS displacements, but the non-crustal deformation component was large in the interferogram generated from ascending data. Based on a fault plane dipping to the southeast, a fault-slip distribution was estimated from the descending interferogram and GPS displacements. The largest fault-slip was located in the southwestern deeper part of the mainshock hypocenter. In the northern part of the focal region, the fault-slip was dominant at depths of 5-15 km, but it was limited to shallower depths in the southern part of the focal region. Such fault-slip distribution is consistent with the aftershock distribution. This consistency supports the assumption that the fault rupture in the mainshock has primarily occurred in the nodal plane dipping to the southeast.
\end{abstract}

Key words: 2007 Chuetsu-oki earthquake, InSAR, PALSAR, coseismic deformation, fault model.

\section{Introduction}

On 16 July 2007, the 2007 Chuetsu-oki earthquake $\left(M_{\mathrm{j}} 6.8\right)$ occurred offshore of Niigata Prefecture, northeast Japan (Fig. 1(a)). This area is a part of the Niigata-Kobe Tectonic Zone (NKTZ) where a high rate of strain accumulation has been detected from the Japanese nationwide GPS array "GEONET" (Sagiya et al., 2000). It is located $50 \mathrm{~km}$ northwest of the focal region of the 2004 Mid Niigata Prefecture earthquake $\left(M_{\mathrm{j}} 6.8\right)$ that occurred on 23 October 2004. According to a nationwide broadband seismograph network (F-net) operated by the National Research Institute for Earth Science and Disaster Prevention (NIED), the focal mechanism was a reverse fault with a compression axis of northwest to southeast, and the direction is roughly consistent with that of the strain accumulation observed by GEONET (Sagiya et al., 2000). Yukutake et al. (2008) applied the double-difference relocation algorithm to derive the precise distribution of aftershocks. Their calculations revealed that the aftershocks were mainly distributed along the nodal plane dipping to the southeast (Fig. 1(b)). A minor aftershock distribution along another nodal plane dipping to the northwest was also indicated. Although the data suggest the possibility that a rupture occurred in both nodal planes, the spatial distribution of the moment tensor (MT) solutions also suggests that the main rupture occurred in the nodal plane dipping to the southeast (Matsumoto et al., 2007).

Coseismic displacements associated with this earthquake were observed by GEONET (Fig. 2). The recordings indi-

Copyright (c) The Society of Geomagnetism and Earth, Planetary and Space Sciences (SGEPSS); The Seismological Society of Japan; The Volcanological Society of Japan; The Geodetic Society of Japan; The Japanese Society for Planetary Sciences; TERRAPUB cated that GPS sites located to the southeast of the epicenter moved to the northwest, in association with the earthquake, and that the displacement increased with decreasing distance to the mainshock epicenter. The northwest area of the epicenter moved to the southeast. Such a displacement pattern is consistent with the displacement field supposed from the focal mechanism. The Japan Aerospace Exploration Agency (JAXA) carried out emergency observation by PALSAR (L-band synthetic aperture radar (SAR) sensor on the ALOS satellite) to gather information about the ground deformation associated with the earthquake. I applied interferometric SAR (InSAR) to detect detailed coseismic deformation. In this paper, I will present crustal deformations obtained from InSAR analysis and the fault model estimated from the ground deformation. In this discussion, I assumed that the main rupture occurred in the nodal plane dipping to the southeast.

\section{Crustal Deformation Obtained by PALSAR InSAR}

PALSAR data acquired from descending orbits on 16 January and 19 July 2007 and those from ascending orbits on 14 June and 14 September 2007 were used in this InSAR analysis. Descending and ascending data were observed by FBS (chirp bandwidth $28 \mathrm{MHz}$ ) and FBD (chirp bandwidth $14 \mathrm{MHz}$ ) modes, respectively. Range resolutions of single look complex images are 4.7 and $9.4 \mathrm{~m}$ for FBS and FBD modes, respectively, but FBD data were resampled to the same resolution as FBS data before InSAR processing. The number of looks of the interferogram is 5 pixels in the range direction and 12 pixels in the azimuth direction, and the obtained interferogram was filtered with a spectrum filter 

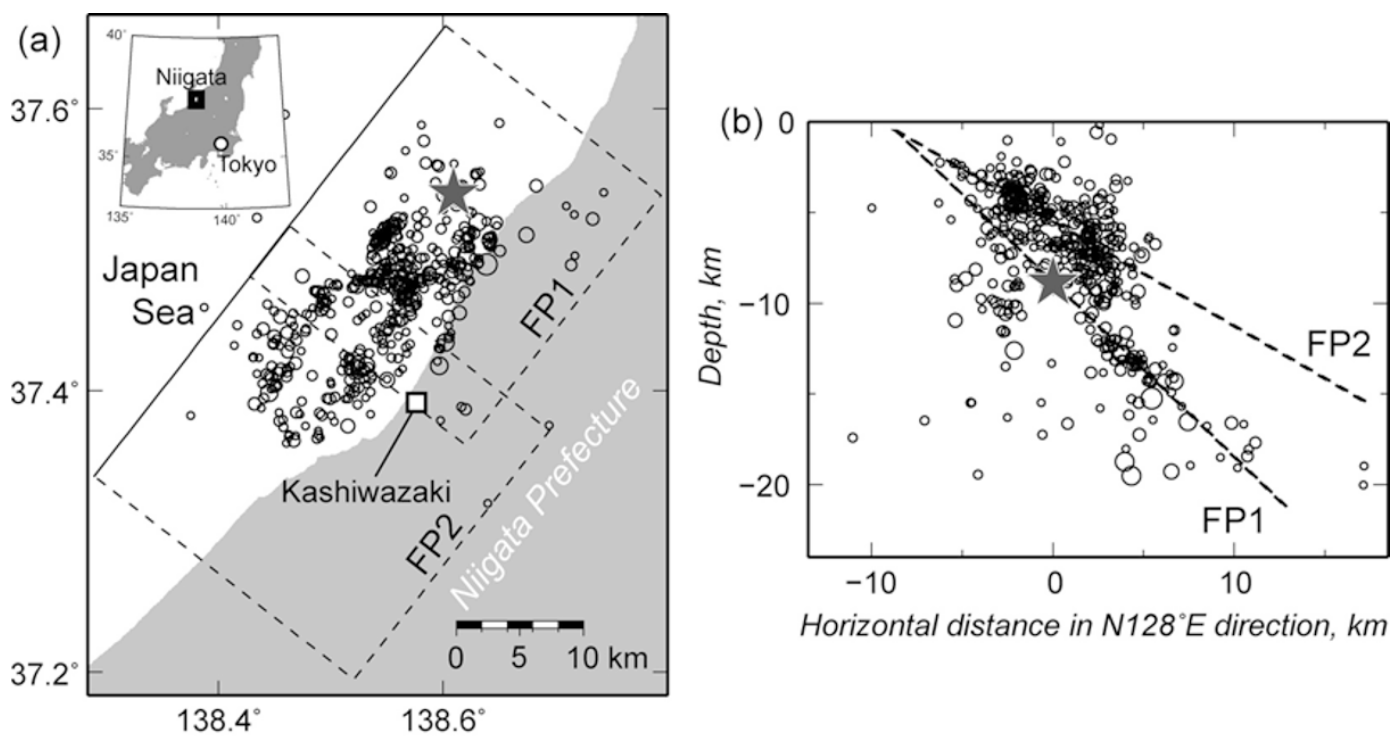

Fig. 1. (a) Aftershock distribution of the 2007 Chuetsu-oki earthquake (Yukutake et al., 2008). Gray star and open circles represent epicenters of the mainshock and aftershocks. FP1 and FP2 (dashed boxes) represent fault planes defined in estimating the fault-slip distribution, and the solid line on each box indicates its upper margin. (b) Cross section of aftershock distribution in the perpendicular plane against the strike direction. Gray star indicates the mainshock epicenter. FP1 and FP2 (broken lines) indicate fault planes defined in estimating the fault-slip distribution.
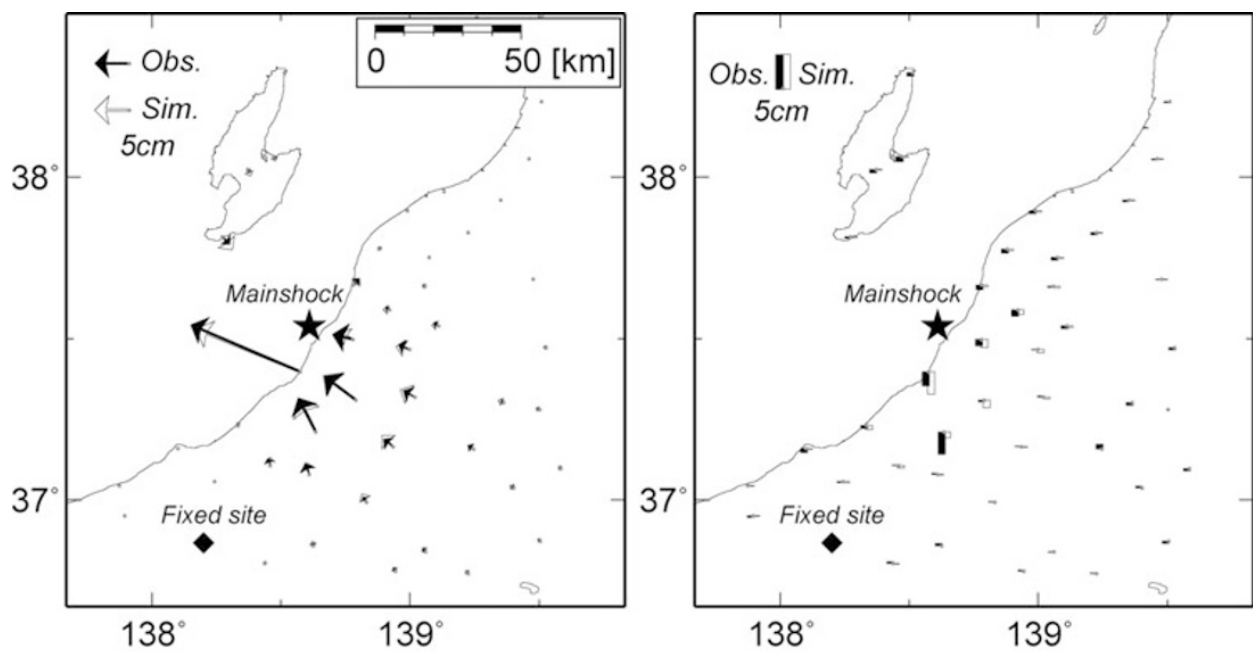

Fig. 2. Coseismic displacements calculated from the GEONET F2 solution. These were estimated by comparing between the averaged coordinates from 6 July 2007 to 15 July 2007 and those from 17 July 2007 to 26 July 2007. Diamond indicates the fixed site of 950247 for the displacement. Star indicates the mainshock epicenter. (a) Solid and white arrows represent the observed and the simulated horizontal displacements. (b) Solid and white bars represent the observed and the simulated vertical displacements.

having a filter parameter of 0.8 and window size of 32 pixels (Goldstein and Werner, 1998). Final results were averaged in pixel sizes of 5.625 and 3.75 arc-seconds for east and north directions, respectively, after the geocoding. The crustal deformation with a $1-\mathrm{km}$ wavelength can then be sufficiently resolved.

The unit vector of line-of-sight (LOS) directions of the radar were $(-0.620 .11-0.78)$ for the descending orbit and $(0.620 .11-0.78)$ for the ascending orbit in the coordinate set (east north up). InSAR can obtain a change of slant ranges between the satellite and the Earth's surface due to crustal deformation during two observations, and the change corresponds to an inner product of a displacement vector and a unit vector of the LOS direction.

Figure 3(a) presents the interferogram generated from the descending data pair. Since the second data set was acquired 3 days after the earthquake, the interferogram may include postseismic deformation. However, as Ohta et al. (2008) observed postseismic deformation of only a few centimeters in 50 days by GPS survey, postseismic deformation in a 3-day period can be ignored in this interferogram. The perpendicular component of the difference of two acquisition positions against the LOS direction (B $\mathrm{B}_{\mathrm{PERP}}$ ) was $-283 \mathrm{~m}$, indicating that conditions were favorable for applying InSAR. Furthermore, an InSAR application using L-band SAR is robust against temporal decorrelation due to vegetation (Rosen et al., 1996), resulting in good coherence, except in highland areas. Decorrelation in highland areas must be due to the effect of snow cover in SAR data acquired on 16 January 2007. Fringe discontinuities 


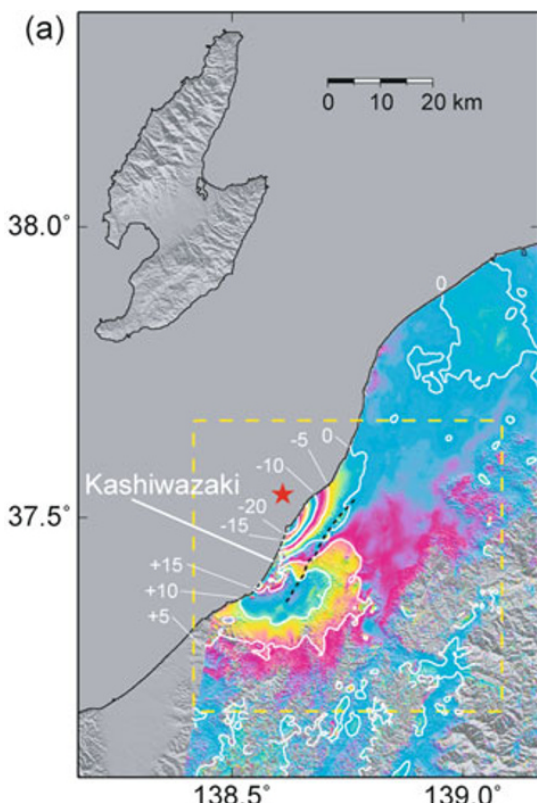

(b)
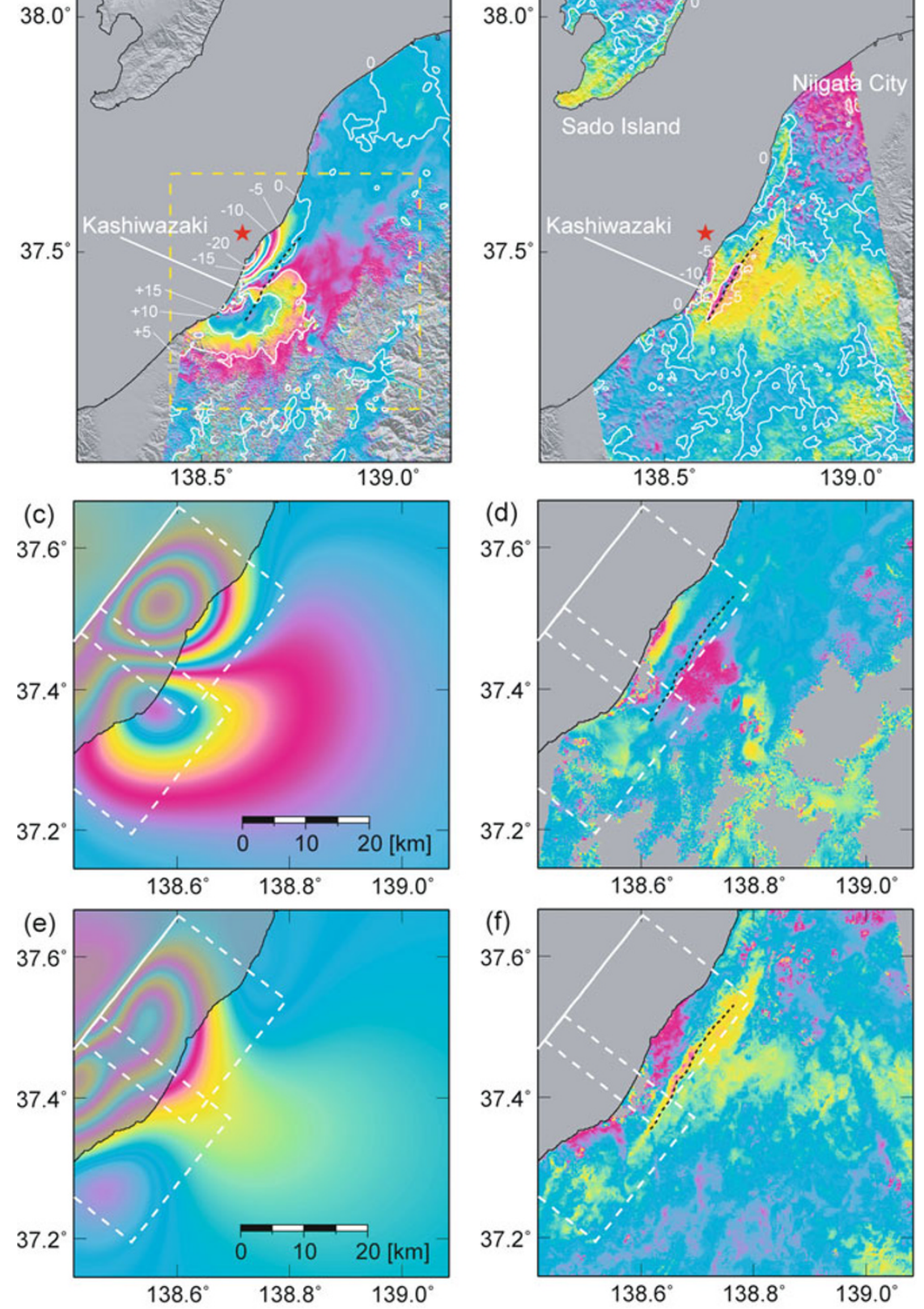

Fig. 3. (a) Observed interferogram for the descending data. Contours indicate slant-range changes every $5 \mathrm{~cm}$. Yellow dashed box represents the area of Figs. 3(c)-(f). Red star indicates the mainshock epicenter. Dashed curve identifies the Oginojyo anticline. (b) Observed interferogram for the ascending data. Color bar indicates a phase difference between $-2 \pi$ and $+2 \pi$, corresponding to a slant-range change between -11.8 and $+11.8 \mathrm{~cm}$. (c) Simulated interferogram for the descending data. Dashed white boxes indicate fault planes defined in estimating the fault-slip distribution. (d) Residual between the observed and the simulated interferogram for the descending data. (e) Simulated interferogram for the ascending data. (f) Residual between the observed and the simulated interferograms for the ascending data.

on the coast of Kashiwazaki correspond to the area where extensive earthquake damage occurred. Since there was no continuity of the fringe in this area, the slant-range change could not be estimated. Slant-range changes obtained from InSAR are consistent with those calculated from GPS displacements. The root-mean-square (rms) of differences is $10 \mathrm{~mm}$, indicating that crustal deformation has been obtained with an accuracy of a few centimeters. Slant-range shortening exceeding $20 \mathrm{~cm}$ was found in the coastal area of Kashiwazaki close to the epicenter. Although the center of this slant-range shortening pattern is masked by sea area, it is presumed that a larger change occurred offshore. The maximum slant-range extension of $15 \mathrm{~cm}$ was detected southeast of the slant-range shortening pattern. Such a fringe pattern is consistent with that supposed from the focal mechanism. 
Table 1. Fault parameters used in the inversion analysis

\begin{tabular}{cccccccc}
\hline & Latitude & Longitude & Depth & Strike & Dip & Length & Width \\
\hline FP1 & $37.4813^{\circ}$ & $138.4277^{\circ}$ & $0.5 \mathrm{~km}$ & $\mathrm{~N} 38^{\circ} \mathrm{E}$ & $44^{\circ}$ & $25 \mathrm{~km}$ & $30 \mathrm{~km}$ \\
$\mathrm{FP} 2$ & $37.3390^{\circ}$ & $138.2890^{\circ}$ & $0.5 \mathrm{~km}$ & $\mathrm{~N} 38^{\circ} \mathrm{E}$ & $30^{\circ}$ & $25 \mathrm{~km}$ & $30 \mathrm{~km}$ \\
\hline
\end{tabular}

Figure 3(b) presents the interferogram generated from ascending data. Since the second data set was acquired 2 months after the earthquake, postseismic deformation of a few centimeters must be included in the interferogram and cannot be ignored. BPERP was $657 \mathrm{~m}$, indicating that InSAR could be sufficiently applied, and the obtained coherence was quite good over the entire image. Comparison between slant-range changes obtained from InSAR and GPS reveals a systematic difference around Niigata City and Sado Island (Figs. 2 and 3). A wavelength exceeding $10 \mathrm{~km}$ and a difference in north Sado Island exceeding $10 \mathrm{~cm}$ indicate a noncrustal deformation component. The difference is not due to an error of the orbit tuning since it cannot be adjusted to the fringe arising from the orbit difference. I therefore suspect that the difference is due to atmospheric and/or ionospheric disturbances (e.g., Goldstein, 1995; Massonnet and Feigl, 1995). A maximum slant-range shortening of $10 \mathrm{~cm}$ was detected in the coastal area of Kashiwazaki, and its wavelength was much shorter than that of the non-crustal deformation component. A slant-range shortening pattern which is characterized by a thin shape extending north and south was also found along the the Oginojyo anticline (dashed curve in Fig. 3(b)). The Geographical Survey Institute of Japan (GSI) found that the anticline was located in the area compressed by the earthquake and proposed that it was uplifted by the compression (Nishimura et al., 2008). Similar fold deformation associated with an earthquake was also found at the earthquake site in southeast Iran (Fielding et al., 2004), and it would relate to the growth of a fold. The investigation of such deformations is the next subject for clarifying the fold growth and the strain accumulation in NKTZ.

\section{Modeling of Fault-slip Distribution}

It is difficult to determine the geometry of the fault plane from inland geodetic data because the hypocenters of the earthquakes are located mainly under the sea. However, the fault plane is well constrained by the aftershock distribution and the MT solution. The strike and dip of the MT solution were determined to be $\mathrm{N} 231^{\circ} \mathrm{E} / \mathrm{N} 38^{\circ} \mathrm{E}$ and $47^{\circ} / 44^{\circ}$, respectively, by F-net observation (Matsumoto et al., 2007), and aftershocks occurred primarily along a nodal plane dipping to the southeast (Yukutake et al., 2008). Aftershocks have also occurred in the southern part of the focal region along the plane dipping to the southeast, but the fault dip angle is $30^{\circ}$, which is less than that of the northern part. Taking these results into consideration, two fault planes dividing the northern and southern parts (FP1 and FP2 of Fig. 1(a)) can be defined in the fault modeling. The defined fault parameters are listed in Table 1. The strikes of these planes are defined as $\mathrm{N} 38^{\circ} \mathrm{E}$, and the dip angles are $44^{\circ}$ and $30^{\circ}$ for FP1 and FP2, respectively. FP1 includes the mainshock hypocenter, and these upper margins of both planes are aligned along the strike direction. The length and width of both planes were set to $25 \mathrm{~km}$ and $30 \mathrm{~km}$, which is sufficiently large relative to the aftershock distribution. Both fault planes are overlapped $5 \mathrm{~km}$ to avoid a marginal effect. These planes are divided into $2.5 \times 2.5 \mathrm{~km}$ fault segments, and the fault-slip vector at each segment was estimated by an inversion analysis based on the Okada model (Okada, 1985) so that crustal deformations obtained from InSAR and GPS are well explained. In this inversion analysis, a smoothness constraint of the fault-slip distribution was used to stabilize the results, and the strength of the constraint was determined so that Akaike's Basian Information Criterion (ABIC, Akaike, 1980) was minimized. Fault-slips on margins of planes are strongly constrained to be zero. Slant-range changes were obtained at more than 26,000 pixels from the descending interferogram, and so it would have been inefficient to input all data into the inversion analysis. Instead, the Quadtree algorithm (Samet and Webber, 1988), which averages displacement data in an adaptive spatial size, was applied. According to the results, the amount of InSAR data was reduced to 235 points. The standard error for InSAR data was assumed to be $15 \mathrm{~mm}$, and its squared inverse was used as the weight of the InSAR data in the inversion analysis. The ascending interferogram was not used in this fault modeling because it includes a large component of non-crustal deformation. Horizontal and vertical components of GPS displacements at 44 sites were the input in this inversion analysis. The standard errors were assumed to be $5 \mathrm{~mm}$ for the horizontal component and $10 \mathrm{~mm}$ for the vertical component, and these squared inverses were used for the weights.

\section{Results and Discussions}

Figure 4 illustrates the estimated fault-slip distribution. The maximum slip $(1.1 \mathrm{~m})$ was estimated in the southwestern deeper area of the mainshock hypocenter in FP1 (white arrow in FP1 of Fig. 4). The rake angle was $71^{\circ}$, corresponding to that of $81^{\circ}$ by the MT solution. Such a fault-slip was dominant at depths of 5-15 km. A significant fault-slip was also estimated in FP2; the maximum one was $0.9 \mathrm{~m}$, and the rake angle was $100^{\circ}$ (white arrow in FP2 of Fig. 4). These results indicate that the main rupture reached the southern area, but that it was limited to the shallower part. The moment magnitude was estimated to be 6.68 , which was a little larger than that of the MT solution. Simulated GPS displacements from the obtained fault model explain the observed displacements well, and these agree within $1 \mathrm{~cm}$ in most sites (Fig. 2). Simulated slant-range changes explain most of the changes obtained from both descending and ascending data, but it is not absolutely accurate (Fig. 3). Slant-range changes of several centimeters remain east of the Oginojyo anticline, and it may be collateral crustal deformation related to the anti- 


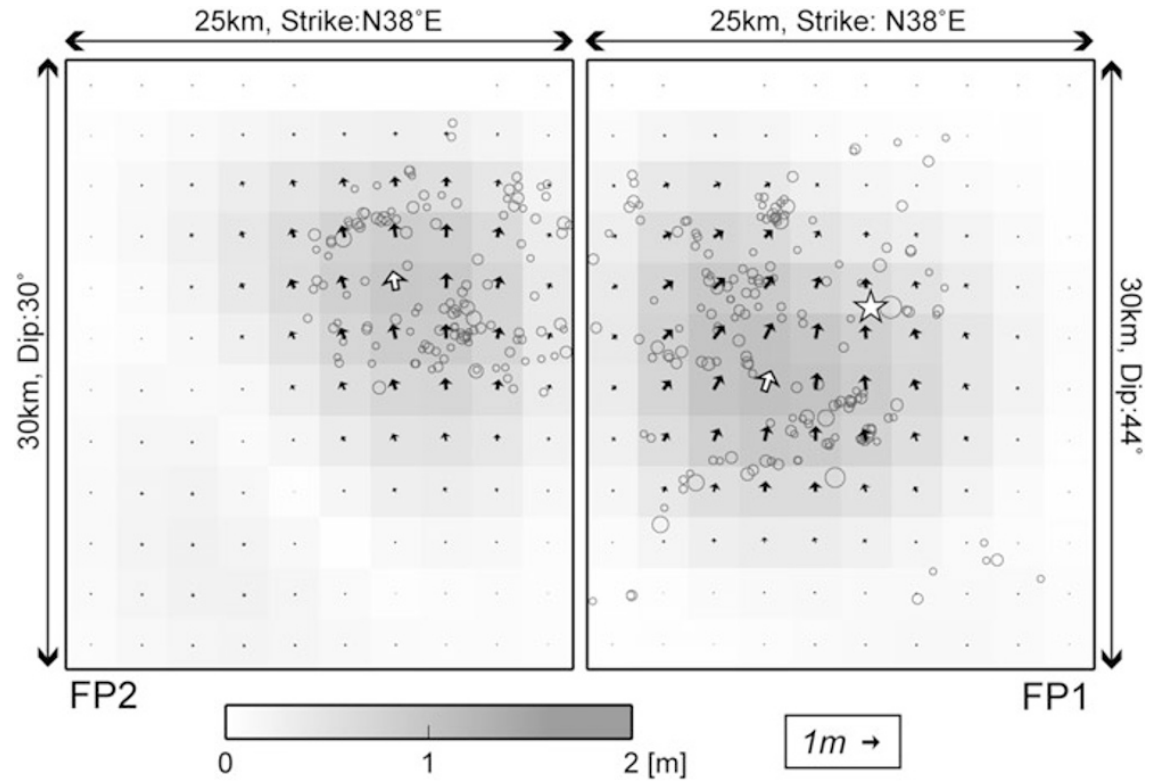

Fig. 4. Fault-slip distribution estimated from descending interferogram and GPS displacements. Color bar indicates the amount of a fault-slip. Solid and white arrows denote the fault slip vectors and maximum slip vectors in FP1 and FP2, respectively. Open circles indicate aftershock hypocenters projected onto the fault plane determined by Yukutake et al. (2008). White star represents the location of the mainshock hypocenter.

cline. It will be solved with the mechanism of deformation along the anticline. Slight residuals of $2-3 \mathrm{~cm}$ were also distributed in the coastal area of Kashiwazaki on both descending and ascending interferograms. One interpretation is that the residual is due to inadequate setting of the fault plane. An aftershock distribution along the northwest dipping plane pointed out by Yukutake et al. (2008) is located just west of the residual pattern. Therefore, a significant fault-slip might also have occurred in the minor fault plane dipping to the northwest. Such collateral deformations may have caused the fault-slip distribution to be improperly estimated. I therefore compared the result with the aftershock distribution for validation. Open circles in Fig. 4 represent aftershock hypocenters projected onto the fault plane. It seems that aftershocks have generally occurred in the area where a fault-slip is significant, but the aftershock activity in a segment where the largest fault-slip was estimated is obviously low. Such a pattern was found in both FP1 and FP2. This may indicate that most of the stress was released by the mainshock and that many aftershocks occurred in the surrounding area due to stress transfer. Thus, the estimated fault-slip distribution is consistent with the aftershock distribution, suggesting that the fault-slip distribution has been resolved well, although minor mismodeling may be included. It also demonstrates that the fault geometry dipping to the east was determined well and supports the assumption that the main rupture occurred in the nodal plane dipping to the southeast.

\section{Summary}

InSAR using PALSAR data was applied to detect crustal deformation related to the 2007 Chuetsu-oki earthquake. Crustal deformation was accurately obtained from descending data, and a slant-range change exceeding $20 \mathrm{~cm}$ was found in the coastal area of Kashiwazaki. A non-crustal deformation component was found in the interferogram from the ascending orbit. Deeper understanding of such noise is an important subject for future InSAR research. A faultslip distribution was estimated from the descending interferogram and GPS displacements based on the assumption that the main rupture occurred in the nodal plane dipping to the southeast. A fault-slip in the northern part of the focal area was dominant at depths of 5-15 km, and a maximum fault-slip of $1.1 \mathrm{~m}$ was obtained in the southwestern deeper part of the mainshock hypocenter. A significant fault-slip extended to the southern part of the focal area, but it was limited to the shallow part. The estimated fault-slip distribution is consistent with the aftershock distribution. This consistency demonstrates that the fault geometry dipping to the east was determined well and supports the assumption that the main rupture occurred in the nodal plane dipping to the southeast.

Acknowledgments. I am grateful to Dr. Eric J. Fielding of the Jet Propulsion Laboratory and Prof. Fumiaki Kimata of Nagoya University for fruitful comments and suggestions. PALSAR level 1.0 data are shared among PIXEL (PALSAR Interferometry Consortium to Study our Evolving Land surface), and provided from JAXA (Japan Aerospace Exploration Agency) under a cooperative research contract with Earthquake Research Institute, University of Tokyo. The ownership of PALSAR data belongs to METI (Ministry of Economy, Trade and Industry) and JAXA. The coordinate data of GEONET F2 analysis was provided by GSI (Geographical Survey Institute of Japan). All figures were drawn using the Generic Mapping Tools from Wessel and Smith (1998).

\section{References}

Akaike, H., Likelihood and Bayes procedure, in Baysian Statistics, edited by J. M. Bernardo et al., 143-166, Univ. Press, Valencia, Spain, 1980. Fielding, E. J., T. J. Wright, J. Muller, B. E. Parsons, and R. Walker, Aseismic deformation of a fold-and-thrust belt imaged by synthetic aperture radar interferometry near Shahdad, southeast Iran, Geol., 32, 577-580, 2004

Goldstein, R., Atmospheric limitations to repeat-track radar interferometry, Geophys. Res. Lett., 22, 2517-2520, 1995. 
Goldstein, R. and C. L. Werner, Radar interferogram filtering for geophysical applications, Geophys. Res. Lett., 25, 4035-4038, 1998.

Massonnet, D. and K. L. Feigl, Discrimination of geophysical phenomena in satellite radar interferograms, Geophys. Res. Lett., 22, 1537-1540, 1995.

Matsumoto, T., H. Matsubayashi, and T. Kazakami, F-net Moment Tensor Solutions on The Niigataken Chuetsu-oki Earthquake in 2007, Abst. Seismol. Soc. Japan, P01-088, 2007.

Nishimura, T., M. Tobita, H. Yarai, T. Amagai, M. Fujiwara, H. Une, and M. Koarai, Episodic growth of fault-related fold in northern Japan observed by SAR interferometry, Geophys. Res. Lett., 35, doi:10.1029/ 2008GL034337, 2008 (in press).

Ohta, Y., S. Miura, T. Iinuma, K. Tachibana, T. Matsushima, H. Takahashi, T. Sagiya, T. Ito, S. Miyazaki, R. Doke, A. Takeuchi, K. Miyao, A. Hirao, T. Maeda, T. Yamaguchi, M. Takada, M. Iwakuni, T. Ochi, I. Meilano, and A. Hasegawa, Coseismic and postseismic deformation related to the 2007 Chuetsu-oki, Niigata Earthquake, Earth Planets Space, 60, this issue, 1081-1086, 2008

Okada, Y., Surface deformation due to shear and tensile faults in a half- space, Bull. Seismol. Soc. Am., 75, 1135-1154, 1985.

Rosen, P. A., S. Hensley, H. A. Zebker, and F. H. Webb, Surface deformation and coherence measurements of Kilauea Volcano, Hawaii, from SIR-C radar interferometry, J. Geophys. Res., 101, 23109-23125, 1996. Sagiya, T., S. Miyazaki, and T. Tada, Continuous GPS array and presentday crustal deformation of Japan, PAGEOPH, 157, 2303-2322, 2000.

Samet, H. and R. E. Webber, Hierarchical data structures and algorithms for computer graphics. I. Fundamentals, IEEE Comput. Graphics Appl. 8-3, 48-68, 1988

Wessel, P. and W. H. F. Smith, New improved version of generic mapping tolls released, EOS Trans. AGU, 79-47, 579, 1998.

Yukutake, Y., T. Takeda, and K. Obara, Well-resolved hypocenter distribution using the double-difference relocation method in the region of the 2007 Chuetsu-oki Earthquake, Earth Planets Space, 60, this issue, 1105-1109, 2008

T. Ozawa (e-mail: taku@bosai.go.jp) 